Agro-Science Journal of Tropical Agriculture, Food, Environment and Extension Volume 10 Number 1 January 2011 nn 1 - 16

ISSN 1119-7455

\title{
AGRICULTURAL INNOVATIONS FOR CLIMATE CHANGE ADAPTATION AND FOOD SECURITY IN WESTERN AND CENTRAL AFRICA
}

\author{
Urama K. and Ozor N. \\ African Technology Policy Studies Network $3^{\text {rd }}$ Floor, The Chancery, Valley Road \\ P. O. Box 10081 -00100 Nairobi, Kenya kurama@atpsnet.org and nozor@atpsnet.org
}

\begin{abstract}
The study sought to examine various agricultural innovations for climate change adaptation and food security in eight countries in Western and Central Africa namely Nigeria, Liberia, Sierra Leone, Ghana, Gambia, Cameroon, Equatorial Guinea and Central African Republic. The countries were grouped into three clusters to facilitate comparative analysis of the data generated. Primary and secondary data were collected using questionnaire, participant observation and focus group discussions while secondary data were obtained through in-depth literature review. Descriptive statistics were mainly employed in data analysis. Results show that the most prominent adaptation measures in Nigeria, Sierra Leone and Liberia were; processing of crops to reduce post-harvest losses; increased weeding; mulching; increased manure application; movement to a different farm site; use of agrochemicals; and prayers for God's intervention. In Ghana and the Gambia, most of the farmers did not do anything but relied on God's intervention. However, others embarked on regular weeding, construction of drainage systems and trenches, and use of agrochemicals. They also referred difficult cases to extension agents. In Cameroon, Equatorial Guinea and the Central African Republic, farmers, resorted to late planting, blocking of drainage in rice fields to conserve water, multiple cropping; planting crops with different maturity periods, use of wood ash, and urban cropping. The study recommends more interaction of relevant stakeholders including farmers, extension agents, civil society actors, private sector actors and government in generating suitable agricultural innovations for climate change adaptation and food security in the regions. Above all, the study identified the need for capacity strengthening at all levels in the agricultural value chain to ensure food security even in the face of climate change.
\end{abstract}

Key words: Climate change, innovation, adaptation, agriculture, food security, Africa

\section{INTRODUCTION}

Global climatic change adversely affects agriculture through long-term alteration in weather patterns, especially increases in temperature and storm activity which are consequences of the greenhouse gas effects. Agricultural productivity worldwide is important as it is a fundamental source of human livelihood. The changes in weather patterns bring uncertainties in the sustainability of agriculture particularly in crop production. The poor countries particularly those in sub Saharan Africa are vulnerable to the impacts of global climate change such as longer periods of drought and an increase in the number, duration and intensity of tropical storms. Challinor et al (2009) noted that uncertainties in regional crop production are not only related to biophysical data, but rather to socio-economic and crop management factors, which affects food security. The economies of most African countries are predominantly agro-based with farming, livestock and forestry accounting for about $40 \%$ of the GDP (FAO, 2008). The impacts of climate change are more pronounced in sub Saharan Africa because agricultural productivity greatly depends on precipitation and natural conditions of the environment. This situation is precipitated by the fact that the changes in climate are taking place in an environment characterized by extreme poverty. Climate change impedes the fight against global poverty because poor people tend to live in the most vulnerable locations with limited means to adapt.

According to the Millennium Development Goals (MDG) Report, (2006), more than 1.2 billion people in the developing world lived in extreme poverty as of 1990. The prevalence of poverty in many countries in the last decade is the core challenge in mitigating the effects of global climate change. With less than 5 years to the target year, available statistics 
cast doubt on whether MDG goal number 1 on eradicating extreme poverty will be achieved by the year 2015. The incidences of food insecurity and poverty are particularly devastating in the developing countries, and a lot of resources are being channeled towards programmes aimed at eradicating food insecurity and poverty by various international organizations and governments of developing nations. While chronic hunger measured by the percentage of people lacking the food needed to meet their daily needs has declined in the developing world, the overall progress is not sufficient enough to reduce the number of people going hungry, which increased between 1995-1997 and 2001-2003 (MDG Report, 2006). An estimated 824 million people were affected by chronic hunger in 2003 of which the worst affected regions were in sub-Saharan Africa and Southern Asia. Although these regions have made strides in addressing food shortages, the number of people going hungry is increasing.

The Intergovernmental Panel on Climate Change (IPCC) 4th Assessment Report (2007) noted that between 75 and 250 million people will be exposed to increased water stress due to climate change by 2020 in Africa and this will adversely affect livelihoods in the region. The land suitable for agriculture, the length of growing seasons and yield potentials are expected to decrease due to climate change. Yields from rain-fed agriculture in some African countries will be reduced by up to $50 \%$. Thus, climate change has serious consequences in Africa, where 800 million people are undernourished. These situations have led to demands in most global, regional, national and local arenas for measures to be put in place to deal with the challenges brought by climate change. This involves the application of innovative adaptive measures to improve the livelihoods particularly of rural farmers who produce the bulk of the food utilized in Africa.

In order to mitigate the impacts of climate change, there is need to take practical measures which reduce vulnerability as global warming and its consequences are imminent and inevitable. It is practical to adapt to climate change when it is gradual and not abrupt to allow individuals and governments time to adjust to the changes. If climate change is abrupt or increases climate variability significantly, it becomes more difficult and costlier to adapt.

Climate change impacts on agriculture demand innovations that can effectively provide and sustain social, economic and environmental resilience of peoples especially the vulnerable groups. Science and technology has enabled the development of these innovations to support agricultural development and livelihood systems of farmers. However, the rapid population growth, high incidences of diseases, low resilience capacity, and poor infrastructure have exacerbated the impact of climate change among farming households in Africa. The projected consequences of climate change imply that subSaharan Africa (SSA) would be drier, and rainfall patterns unreliable. As most of the arable land is already under cultivation, expansion in the food production will require agricultural technologies and innovations such as high yielding disease tolerant seeds, irrigation technology and sustainable agricultural practices to withstand the catastrophic impacts of climate change. It will require intensification of research in agricultural science, technology and innovation systems. The innovation system approach offers a more holistic, multidisciplinary and comprehensive framework for climate change adaptation to ensure food security. Of much importance in agricultural innovations for climate change adaptation is stakeholder participation, linkages and institutional contexts in the processes (AkonYamga et al, 2011). This means that climate change presents challenges to agriculture which cannot be addressed in isolation and hence demands concrete innovative steps to reduce vulnerability and enhance adaptive capacity of poor people. These actions entail adaptation which refers to consciously planned adjustments in a system to reduce, moderate, or take advantage of the expected negative impacts of climate change. Adaptation is intended to help farmers achieve food, income and livelihood security, to avoid devastating implications for agriculture and livelihood.

Based on the foregoing, the study sought to examine various agricultural innovations for climate change adaptation and food security in western and central Africa using empirical data from eight countries including Nigeria, Liberia, Sierra Leone, Ghana, Gambia, Cameroon, Equatorial Guinea, and Central African Republic.

\section{Purpose and Objectives}

The overall purpose of the study was to identify and document effective agricultural innovations for climate change adaptation and food security in western and central Africa. Specifically, the study was meant to:

1. characterize the respondents in the study area;

2. determine farmers' awareness and knowledge of climate change;

3. identify the sources of information for innovations on climate change adaptation and food security; 
4. ascertain agricultural extension activities towards climate change adaptation; and

5. identify the indigenous and emerging agricultural innovations for climate change adaptation and food security.

\section{METHODOLOGY}

The research is based on desk research and field survey which was carried out in 2010 in eight African countries namely Nigeria, Ghana, Equatorial Guinea, Gambia, Liberia, Sierra Leone and Central African Republic. The countries are located in Western and Central Africa. The countries were stratified into clusters to extract as much information as possible and also to facilitate the comparison of the variables. In this regard, the research was conducted in three groups of countries namely;

Group 1- Nigeria, Sierra Leone and Liberia

Group 2-Ghana and the Gambia

Group3-Cameroon, Equatorial Guinea and Central Africa Republic

\section{Desk Study}

The desk study was undertaken to review the literature and examine reports, papers, and official documents prior to the commencement of the research. This was to provide background and existing information and data on the subject matter. The documents were mainly obtained from relevant ministries, departments and agencies in the countries that constituted the case studies. The World Wide Web was relied on as a source of secondary data to complement the information obtained.

\section{Field Survey}

The field survey entailed the administration of questionnaire instruments to heads of farming households or their representatives. The administration of questionnaire instruments at the household level was complemented by focus group discussions organized at the district levels with farmers

\section{Population and Sample Size}

In Nigeria, Sierra Leone and Liberia, respondents were selected through a multistage sampling technique. In the first stage, thirteen states namely Abia, Adamawa, Borno, Cross Rivers, Delta, Enugu, Gombe, Imo, Kogi, Ondo, Oyo, Plateau and Yobe States were selected from the seven agro-ecological zones in Nigeria. In Sierra Leone, six districts namely Freetown Peninsula, Kailahun, Bo, Koinadugu, Moyamba and Free Town Coastal Plain districts were selected from the four agro-climatic regions, while seven counties namely Nimba, Bong,
Lofa, Grand Bassa, Margibi, Grand Cape Mount and Grand Gedeh were selected from the four agro-climatic regions, in Liberia.

In the second stage for the Nigeria case, using the delineation by the different states' Agricultural Development Programmes (ADPs) in Nigeria, two agricultural zones were randomly selected from each state giving a total of 26 agricultural zones in Nigeria. From each of the selected zones, 25 farming households were randomly selected from a list provided by extension agents for interview. This gave a total of 650 farming households from Nigeria. In Sierra Leone, a sample size of 70 farming households was randomly selected from each of the six districts giving a total of 420 households; while in Liberia 60 farming households were randomly selected from each of the counties surveyed, giving a total of 420 farming households.

The sample of farming households for this study was selected through a combination of strategies that recognized the social component of indigenous knowledge and practices. Criteria used for selection included age (for historical insight on indigenous knowledge), farming experience and interest. Inall, a total of 1,490 farming households were interviewed. However, 1,424 (624 from Nigeria); (400 from Sierra Leone) and (400 from Liberia) completely filled interview schedules were used for data analysis

To allocate the number of household heads to interview in Ghana and the Gambia, a ratio of the populations of the two countries was used. Therefore relying on the ratio of the population of Ghana $(23,350,927)$ to the Gambia $(1,660,200)$ as the basis for allocating the number of households to be selected from each country, 747 households were allocated to Ghana and 53 households were allocated to Gambia in order to meet the proposed overall sample size of 800 . However it was realized that 53 households were too low a sample and therefore during the survey 100 households were selected from the Gambia while 746 households were selected from Ghana. In order to increase precision and reliability of the data and results of the survey, stratification was employed. This was done by taking into consideration the geographical distribution, ecological zones and population distribution as the main control. In both countries, districts were grouped according to their administrative regions. In Ghana, one district was selected within each region using the simple random sampling technique. In the Gambia, however, two regions were randomly selected initially and within these two regions, one district each was selected using the simple random sampling. 
Once a district was selected, a list of five major food producing communities was obtained from the state ministry or department responsible for agriculture. From this list some communities were randomly selected. The number of communities selected per ecological zone or district depended on the total population per community and the total sample per ecological zone. At the community level, an enlistment of the households was conducted with the assistance of an opinion leader in the community. This provided the sampling frame of households at the community level from which the households interviewed were randomly selected.

With regards to Cameroon, Central African Republic and Equatorial Guinea, sampling was done in the agro-ecological zones of the respective countries. These zones show distinct ecological diversity with Cameroon having five, the Central African Republic three and Equatorial Guinea two. All the agroecological zones in Central African Republic and Equatorial Guinea are represented in Cameroon such that trends observed in Cameroon could be extrapolated to the other countries. As a result, Cameroon had more sample targets (600) than Central African Republic and Equatorial Guinea that had 200 each. Out of the 600 copies of the questionnaire instruments administered in Cameroon, only 572 were retrieved for analysis. The 200 distributed in the Central African Republic were all retrieved while only 115 of the 200 copies administered in Equatorial Guinea were recovered for analysis.

\section{Data Collection Techniques}

Structured questionnaire, semi-structured interview schedule, key informant interviews and focus group discussions (FGDs) were used in primary data collection. The instrument contained both open ended and semi-structured questions. The questionnaire instruments characterized the respondents according to socioeconomic features and determined farmers' awareness and knowledge of climate change. It also identified the various sources of information on climate change adaptation and food security and ascertained the agricultural extension activities carried out towards climate change adaptation. Finally, the instrument sought to identify the indigenous and emerging innovations for climate change adaptation and food security in the study area.

\section{Data Analysis}

Objective one was analyzed using percentage and mean scores while objective two was analyzed using trend analysis, graphs and percentage scores. Objective three was analyzed using mean scores and standard deviation while objective four was analyzed using bar charts and percentage scores. Finally, objective five was analyzed using percentage scores.

\section{RESULTS AND DISCUSSIONS}

Selected socioeconomic characteristics of farmers

Age

The mean age of farmers in Nigeria, Sierra Leone and Liberia was 47, 45 and 43, respectively. This indicates that the respondents were predominately in their middle age bracket and hence are in their most productive stage of life that can enhance agricultural productivity. In Ghana, majority of farmers $(63 \%)$ were below 50 years which is still in line with the findings from the other West African countries earlier mentioned. However, in Gambia, the story was not the same as $84 \%$ of farmers were above the age of 40 years. The implication for the agricultural sector in the Gambia is that the country may not be realising its potential in agricultural production as the active age groups are not engaged in agriculture. Majority (38\%, $37 \%$, and $52 \%$ ) of farmers in Cameroon, Equatorial Guinea and Central African Republic respectively were in the age range of 41-50 years. This also implies that farmers in this central African region are in their most productive age and have the requisite energy to face the drudgery that characterizes African agriculture due to lack of modern farm equipment and facilities.

\section{Gender}

Results show that there was male dominance among the household heads involved in agriculture in the eight countries studied. A breakdown of the findings by countries show that men constituted about $81 \%, 77 \%$, and $67 \%$ of household heads who were farmers in Nigeria, Sierra Leone and Liberia, respectively. Also in Ghana and the Gambia, $76 \%$ and $92 \%$ of household heads, respectively who were farmers were men. Again in Cameroon, Equatorial Guinea and Central African Republic, the percentage of farmers who were household heads were $79 \%, 87 \%$ and $83 \%$, respectively. The result shows that efforts to increase agricultural production in Africa will need specially tailored programmes for the women who provide about $70 \%$ of the farm labour force and $80 \%$ of food processing activities in Africa (Adisa and Okunade, 2005).

\section{Educational qualification}

Results show a wide variation in the literacy levels of farmers in the countries studied. While 
about $86 \%$ and $63 \%$ of farmers in Nigeria and Liberia possessd one form of educational qualification or the other, only about $41 \%$ had it in Sierra Leone. In Ghana and the Gambia, about $62 \%$ and $100 \%$ of farmers, respectively had one form of formal education or the other. Most specifically in Gambia, majority $(62 \%)$ of the literate farmers had received Arabic education. In Cameroon, Equatorial Guinea and Central African Republic, about 83\%, 74\% and 96\%, respectively received one form of formal education or the other. Generally, there appeared to be a relatively high literacy level in all the countries studied. This has implications for adoption of agricultural innovations for climate change adaptation as studies have shown that high educational statuses of farmers do positively influence their adoption of improved technologies and practices (Agwu and Anyanwu, 1996). Literacy also enables farmers to take effective steps towards climate change adaptation options (Ozor and Nnaji, 2010).

Information on specialized training on climate change and food security in the areas reveals that only $2 \%, 3 \%$ and $1 \%$ of farmers from Nigeria, Sierra Leone and Liberia, respectively had received any form of specialized trainings on climate change adaptation and food security mainly from nongovernmental organizations. The story was the same in Ghana and the Gambia where only $2.6 \%$ and $4 \%$ respectively had received specialized trainings. In Cameroon, Equatorial Guinea and Central African Republic, about 32\%, 15\% and $8 \%$, respectively had received specialized trainings. The consistent low level of capacity development on climate change adaptation in the study areas shows the level of efforts required by governments to boost the capacity of African farmers to be able to adapt effectively and efficiently to climate change impacts in order to produce enough food for the teeming population.

\section{Farming experience}

Most farmers (34\% and 39\%) in Nigeria and Sierra Leone, respectively had had between 11 to 20 years of farming experience while most farmers $(47 \%)$ in Liberia had only one to ten years of farming experience. Also in Cameroon and Equatorial Guinea, about $34 \%$ and $44 \%$ of farmers, respectively had 11 to 20 years of farming experience, while in the Central African Republic about $44 \%$ of farmers had 21 to 30 years of farming experience. Long experience in farming affords farmers the opportunity to develop innovative ideas to adapt to changes associated to weather and climate. According to Ozor and Nnaji (2010), farmers with long years of farm experience may have acquired wealth of knowledge on the indigenous adaptive measures for cushioning the effects of climate change as well as identifying obstacles for effective adaptation.

\section{Size of farm}

In Nigeria, Sierra Leone, Liberia, Ghana, Cameroon, Equatorial Guinea and Central African Republic, most farmers (78\%, 99\%, $99 \%, 81.5 \%, 78 \%, 99 \%$ and $98 \%$, respectively) own small size of farms of less than 5 hectares while $51 \%$ of farmers in Gambia owned medium size of farms. The system of land ownership and tenure system may have contributed in the small sizes of farms owned by most farmers in the study area. Farmers noted in the FGD conducted that other reasons that might contribute to the small size of farms were low income levels, high cost of labour, lack of agro inputs, lack of access to credit facilities, and poor development of the value chain system.

\section{Type of farming}

Most farmers in the countries studied engaged in crop farming. About 94.5\%, 98.5\%, 98.3\%, $99 \%, 54 \%, 89.5 \%, 99.1 \%$, and $96.1 \%$ of the respondents were crop farmers in Nigeria, Sierra Leone, Liberia, Ghana, Gambia, Cameroon, Equatorial Guinea, and Central African Republic, respectively. The dominance crop farming was as a result of its supply of daily food needs for subsistence and sometimes for commercial purposes.

\section{Farmers' awareness and knowledge of climate change phenomenon in agriculture}

Results from the regional study have shown an increased awareness and knowledge of climate change phenomenon among rural farmers. Farmers in Nigeria, Sierra Leone and Liberia showed a high level of awareness and knowledge of climate change phenomenon in agriculture with respect to observed incidences at the onset of farming season, extreme weather events and other farming problems which were attributed to climate change. Results on climate change phenomenon as perceived by the farmers further show that there were more uncertainties at the onset of farming seasons since 2006 in Liberia than in Nigeria and Sierra Leone as a result of unusual early rains that were followed by weeks of dryness; erratic rainfall pattern; delay in the onset of rains; long period of dry seasons; long period of rainfall in some areas; short period of rainfall in other areas and reduced period of harmattan. Again, data in Figure 1 show that farmers in Liberia experienced the highest increases in the trend of extreme events occasioned by thunderstorms, heavy winds, flooding, heavy rainfall and 
erosion, among other weather events since 2006 than in Nigeria and Sierra Leone.

The perceived trends in farming problems including disease incidences, weed infestations, soil infertility, over flowing/ drying up of streams / rivers, low farm yields and landslides were mostly observed in Liberia between 2006 and 2009 than in Nigeria and Sierra Leone. This trend is shown in Figure 2.

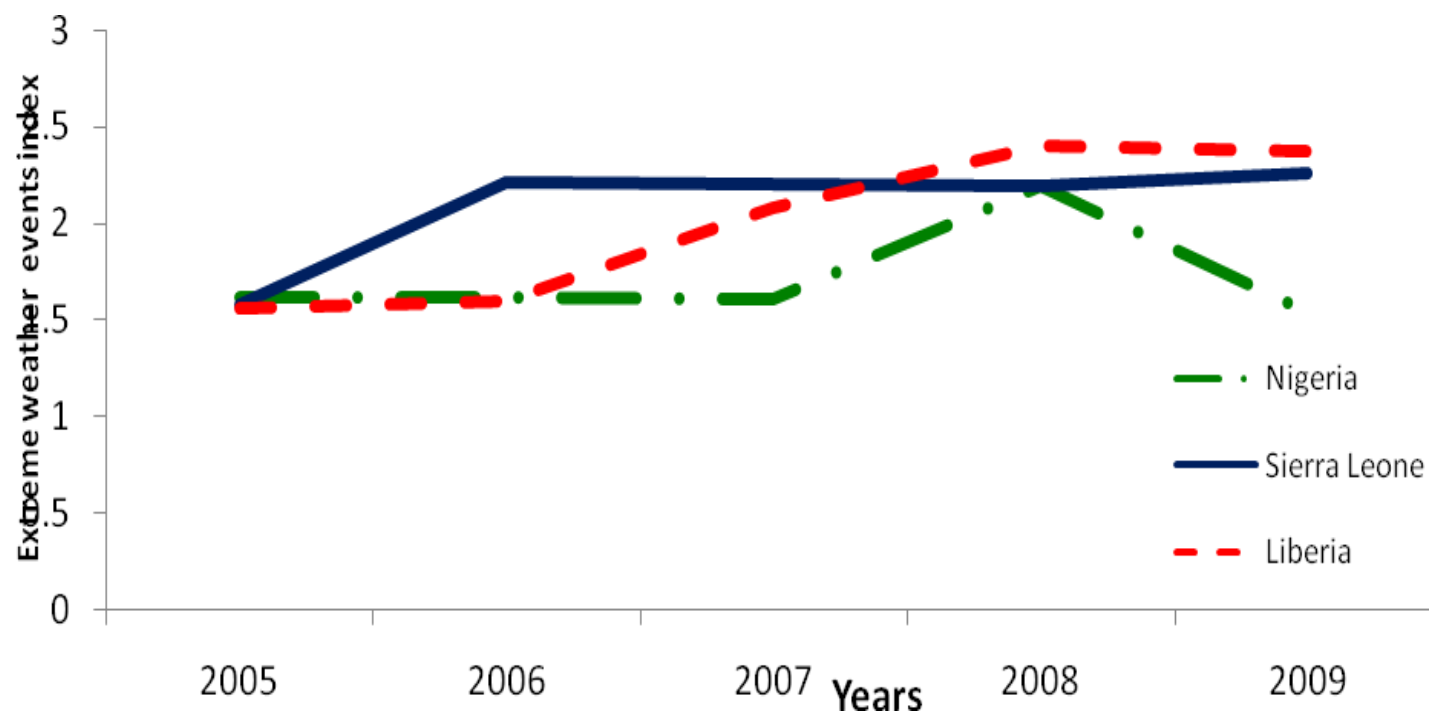

Figure 1: Perceived trend in extreme weather events in Nigeria, Sierra Leone and Liberia Source: Agwu et al 2011

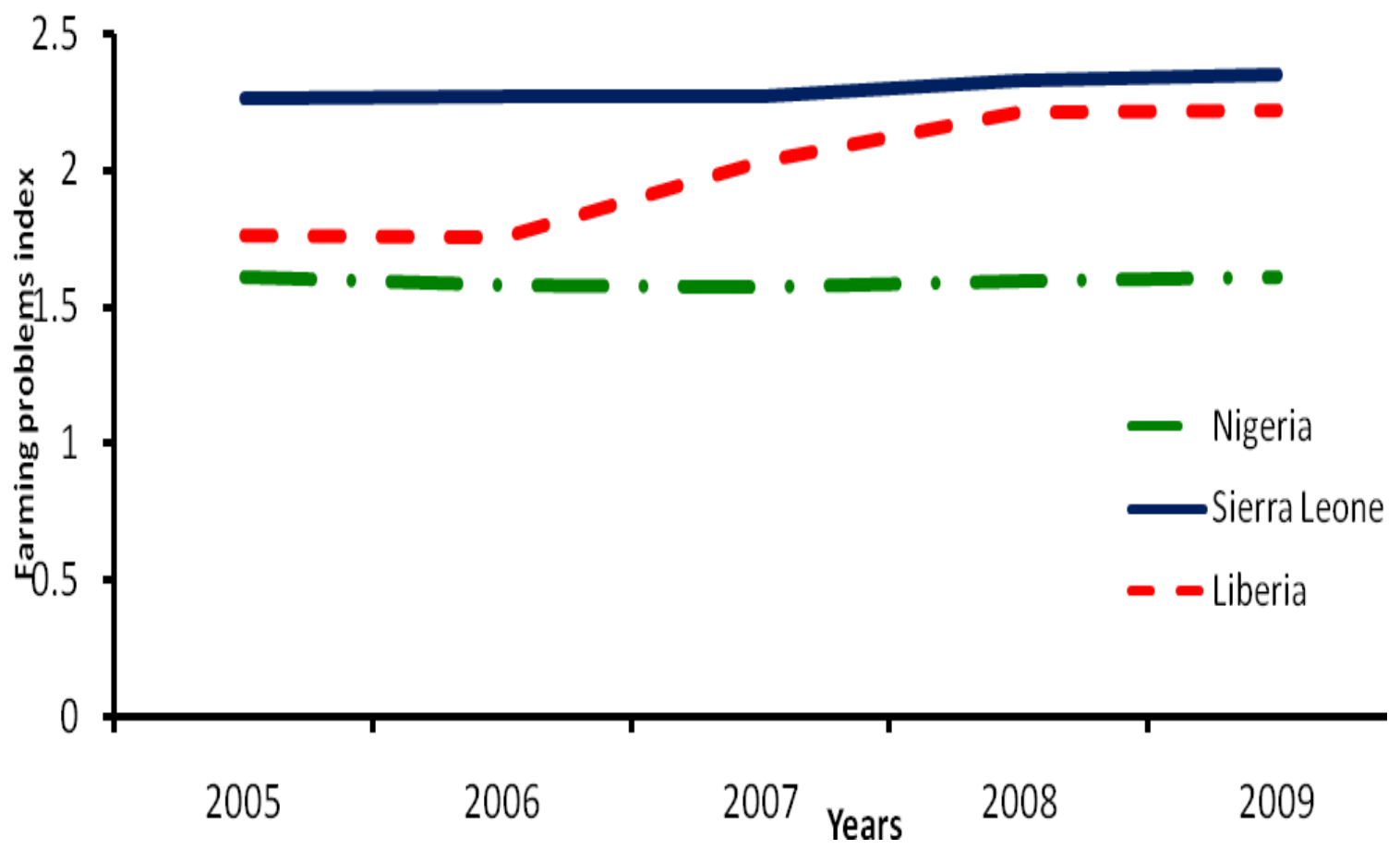

Figure 2: Perceived trends in farming problems among farmers in Nigeria, Sierra Leone and Liberia Source: Agwu et al, 2011 
In Ghana and the Gambia, the level of farmers' awareness and knowledge of climate change phenomenon was also high $(60 \%$ and $91 \%$, respectively). On their experiences with changes in weather events, about $57 \%$ of farmers in Ghana indicated that rain did not fall at the usual time during the previous planting seasons it did not rain at the right time at the last planting season. On the other hand, farmers in Gambia did not experience any significant change in the onset of rains during the previous planting seasons. Other observed changes in weather events in Ghana and Gambia were the loss of vegetation cover and wildlife and increase in incidences of pests and diseases. Farmers' awareness and knowledge of climate change phenomenon in the central African region (Cameroon, Equatorial Guinea and Central African Republic) was also high with a record of $51.6 \%, 54 \%$ and $100 \%$ in the three respective countries studied. For the central African region, farmers noted that the trend of uncertainties in the onset of farming seasons, extreme weather events, and farming problems had generally increased within the past five years as shown in Tables 1 - 3.

Table 1: Trends of uncertainties in the onset of farming season in Central Africa from 2005 to 2009

\begin{tabular}{|c|c|c|c|c|c|}
\hline Weather events & 2005 & 2006 & 2007 & 2008 & 2009 \\
\hline \multicolumn{6}{|c|}{ Unusual early rains that are followed by weeks of dryness } \\
\hline Same & 48.0 & 44.7 & 29.5 & 19.1 & 15.9 \\
\hline Declined & 19.6 & 19.1 & 21.9 & 18.0 & 20.7 \\
\hline Increased & 32.4 & 36.2 & 48.6 & 62.9 & 63.4 \\
\hline \multicolumn{6}{|c|}{ Erratic rainfall pattern } \\
\hline Same & 37.8 & 34.3 & 23.5 & 15.4 & 13.9 \\
\hline Declined & 23.5 & 23.0 & 18.3 & 14.4 & 13.9 \\
\hline Increased & 38.7 & 42.7 & 58.2 & 70.2 & 72.2 \\
\hline \multicolumn{6}{|c|}{ Delay in the unset of rains } \\
\hline Same & 37.6 & 32.3 & 24.3 & 13.5 & 12.1 \\
\hline Declined & 31.8 & 35.7 & 33.3 & 23.3 & 26.5 \\
\hline Increased & 30.6 & 32.0 & 42.4 & 63.2 & 61.4 \\
\hline \multicolumn{6}{|c|}{ Long period dry season } \\
\hline Same & 37.3 & 33.9 & 26.1 & 13.1 & 8.1 \\
\hline Declined & 16.1 & 19.3 & 17.1 & 12.6 & 14.3 \\
\hline Increased & 46.6 & 46.8 & 56.8 & 74.3 & 77.6 \\
\hline \multicolumn{6}{|c|}{ Long period of rainfall } \\
\hline Same & 35.4 & 32.0 & 24.6 & 16.3 & 13.9 \\
\hline Declined & 43.4 & 42.7 & 49.4 & 55.1 & 55.7 \\
\hline Increased & 21.2 & 25.3 & 26.0 & 28.6 & 30.4 \\
\hline \multicolumn{6}{|c|}{ Short period of rainfall } \\
\hline Same & 42.5 & 39.0 & 32.3 & 23.7 & 19.7 \\
\hline Declined & 21.3 & 23.0 & 19.0 & 16.7 & 18.3 \\
\hline Increased & 36.2 & 38.0 & 48.7 & 59.6 & 62.0 \\
\hline \multicolumn{6}{|c|}{ Reduced harmattan } \\
\hline Same & 65.4 & 61.8 & 58.9 & 51.7 & 46.6 \\
\hline Declined & 17.8 & 19.4 & 19.3 & 20.7 & 21.2 \\
\hline Increased & 16.8 & 18.8 & 21.8 & 27.6 & 32.2 \\
\hline \multicolumn{6}{|c|}{ Long period of harmattan } \\
\hline Same & 59.9 & 56.3 & 54.3 & 50.0 & 42.8 \\
\hline Declined & 22.8 & 23.0 & 20.9 & 18.5 & 24.8 \\
\hline Increased & 17.3 & 20.7 & 24.8 & 31.5 & 32.4 \\
\hline
\end{tabular}

Source: Ngoh et al, 2011 
Table 2: Trends in extreme weather events in Central Africa from 2005 to 2009

\begin{tabular}{|c|c|c|c|c|c|}
\hline Extreme weather events & 2005 & 2006 & 2007 & 2008 & 2009 \\
\hline \multicolumn{6}{|l|}{ Thunderstorms } \\
\hline Same & 51.2 & 48.8 & 43.9 & 36.9 & 33.1 \\
\hline Declined & 29.4 & 29.2 & 28.3 & 25.2 & 25.5 \\
\hline Increased & 19.4 & 22.0 & 27.8 & 37.9 & 41.4 \\
\hline \multicolumn{6}{|l|}{ Heavy winds } \\
\hline Same & 43.2 & 39.6 & 33.6 & 23.5 & 18.2 \\
\hline Declined & 27.5 & 27.5 & 27.0 & 19.9 & 20.7 \\
\hline Increased & 29.4 & 32.9 & 39.4 & 56.7 & 61.1 \\
\hline \multicolumn{6}{|c|}{ Incidence of dust covering the atmosphere } \\
\hline Same & 49.0 & 46.7 & 42.6 & 34.9 & 26.8 \\
\hline Declined & 16.4 & 16.5 & 15.4 & 13.6 & 10.5 \\
\hline Increased & 34.5 & 36.9 & 42.0 & 51.5 & 62.6 \\
\hline \multicolumn{6}{|l|}{ Flooding } \\
\hline Same & 49.7 & 48.2 & 45.0 & 43.0 & 40.5 \\
\hline Declined & 36.1 & 36.1 & 37.4 & 38.1 & 39.9 \\
\hline Increased & 14.2 & 15.7 & 17.6 & 18.9 & 19.5 \\
\hline \multicolumn{6}{|l|}{ Drought } \\
\hline Same & 33.4 & 34.8 & 27.8 & 18.6 & 14.0 \\
\hline Declined & 11.5 & 9.6 & 8.9 & 8.3 & 9.2 \\
\hline Increased & 55.0 & 55.5 & 63.3 & 73.1 & 76.8 \\
\hline \multicolumn{6}{|l|}{ Erosion } \\
\hline Same & 47.9 & 47.3 & 42.6 & 37.4 & 35.7 \\
\hline Declined & 19.6 & 18.5 & 18.7 & 18.3 & 19.4 \\
\hline Increased & 32.5 & 34.2 & 38.7 & 44.3 & 44.9 \\
\hline \multicolumn{6}{|l|}{ Heat waves } \\
\hline Same & 43.4 & 39.7 & 36.5 & 26.3 & 24.9 \\
\hline Declined & 14.2 & 14.2 & 11.5 & 10.0 & 9.8 \\
\hline Increased & 42.4 & 46.1 & 52.0 & 63.7 & 65.3 \\
\hline \multicolumn{6}{|l|}{ High Sun intensity } \\
\hline Same & 34.1 & 31.2 & 23.8 & 14.9 & 11.7 \\
\hline Declined & 11.7 & 11.6 & 7.6 & 6.2 & 6.0 \\
\hline Increased & 54.2 & 57.2 & 68.7 & 78.8 & 82.3 \\
\hline \multicolumn{6}{|l|}{ Heavy rainfall } \\
\hline Same & 29.0 & 26.1 & 19.3 & 15.9 & 12.7 \\
\hline Declined & 40.9 & 40.8 & 45.9 & 43.2 & 43.9 \\
\hline Increased & 30.1 & 33.1 & 34.8 & 40.9 & 43.4 \\
\hline \multicolumn{6}{|c|}{ Desertification or loss of forest resources } \\
\hline Same & 27.0 & 27.1 & 13.4 & 9.3 & 8.8 \\
\hline Declined & 11.3 & 11.1 & 8.5 & 7.8 & 7.5 \\
\hline Increased & 61.8 & 61.8 & 78.1 & 82.9 & 83.8 \\
\hline \multicolumn{6}{|c|}{ Volume of sand encroachment } \\
\hline Same & 62.6 & 61.4 & 55.5 & 50.4 & 46.9 \\
\hline Declined & 23.0 & 23.7 & 23.3 & 20.3 & 21.3 \\
\hline Increased & 145 & 14.8 & 21.2 & 29.2 & 31.8 \\
\hline
\end{tabular}

Source: Ngoh et al, 2011 
Table 3: Trends on selected farming problems in Central Africa from 2005 to 2009

\begin{tabular}{|c|c|c|c|c|c|}
\hline Selected farming problems & 2005 & 2006 & 2007 & 2008 & 2009 \\
\hline \multicolumn{6}{|l|}{ Disease incidence } \\
\hline Same & 31.9 & 31.6 & 18.3 & 11.7 & 9.6 \\
\hline Declined & 15.5 & 14.6 & 16.4 & 10.6 & 8.9 \\
\hline Increased & 52.6 & 53.8 & 65.3 & 77.7 & 81.6 \\
\hline \multicolumn{6}{|l|}{ Weed infestation } \\
\hline Same & 36.5 & 36.9 & 29.0 & 22.8 & 20.0 \\
\hline Declined & 16.8 & 15.4 & 13.9 & 11.1 & 10.7 \\
\hline Increased & 46.7 & 47.7 & 57.2 & 66.1 & 69.3 \\
\hline \multicolumn{6}{|l|}{ Soil infertility } \\
\hline Same & 35.9 & 34.6 & 26.1 & 20.0 & 18.0 \\
\hline Declined & 23.4 & 24.1 & 24.6 & 24.1 & 24.8 \\
\hline Increased & 40.7 & 41.4 & 49.4 & 56.0 & 57.2 \\
\hline \multicolumn{6}{|l|}{ Drying up of streams / rivers } \\
\hline Same & 32.5 & 32.4 & 27.2 & 17.9 & 15.3 \\
\hline Declined & 11.2 & 11.3 & 10.8 & 9.0 & 10.4 \\
\hline Increased & 56.2 & 56.3 & 62.0 & 73.1 & 74.3 \\
\hline \multicolumn{6}{|c|}{ Overflowing of streams / rivers } \\
\hline Same & 35.2 & 35.7 & 28.8 & 20.9 & 18.5 \\
\hline Declined & 49.2 & 48.6 & 51.3 & 56.4 & 56.1 \\
\hline Increased & 15.6 & 15.8 & 19.9 & 22.7 & 25.5 \\
\hline \multicolumn{6}{|l|}{ Farm yields } \\
\hline Same & 38.8 & 37.2 & 25.3 & 16.4 & 17.0 \\
\hline Declined & 31.3 & 31.8 & 39.1 & 49.5 & 49.6 \\
\hline Increased & 29.9 & 31.1 & 35.7 & 34.1 & 33.5 \\
\hline \multicolumn{6}{|l|}{ Land slides } \\
\hline Same & 48.0 & 47.2 & 45.7 & 43.6 & 41.0 \\
\hline Declined & 40.9 & 40.2 & 40.2 & 42.1 & 41.0 \\
\hline Increased & 11.0 & 12.6 & 14.2 & 14.3 & 17.9 \\
\hline
\end{tabular}

Ngoh et al, 2011

Table 4: Sources of information on agricultural innovations for climate change adaptation and food security in Nigeria, Sierra Leone and Liberia $(n=624,400$ and 400 respectively)

\begin{tabular}{|c|c|c|c|c|c|c|}
\hline \multirow[t]{2}{*}{ Sources of information } & \multicolumn{2}{|l|}{ Nigeria } & \multicolumn{2}{|c|}{ Sierra Leone } & \multicolumn{2}{|c|}{ Liberia } \\
\hline & Mean & SD & Mean & SD & Mean & SD \\
\hline Radio & $3.02 *$ & 0.95 & $3.44 *$ & 1.31 & 2.66 & 1.28 \\
\hline Television & 2.74 & 1.10 & $3.06^{*}$ & 1.12 & 1.49 & 1.05 \\
\hline Fellow Farmers & $3.08^{*}$ & 1.17 & 2.84 & 0.92 & 2.10 & 1.13 \\
\hline Meetings / seminars / trade fairs & 2.98 & 1.34 & 2.76 & 1.30 & 1.83 & 1.14 \\
\hline Extension Officers & 2.44 & 1.45 & 2.64 & 0.81 & 1.68 & 0.92 \\
\hline Government Researchers & 2.43 & 1.39 & $3.38 *$ & 1.77 & 1.50 & 0.81 \\
\hline $\begin{array}{l}\text { Input suppliers e.g. seed, fertilizer } \\
\text { companies }\end{array}$ & 2.71 & 1.34 & 1.00 & 0.00 & 1.40 & 0.58 \\
\hline University & 2.74 & 1.52 & 1.00 & 0.00 & 1.59 & 0.83 \\
\hline Internet & 2.44 & 1.43 & 1.00 & 0.00 & 1.36 & 0.81 \\
\hline $\begin{array}{l}\text { Ministries of Agriculture } \\
\text { Ministries of Environment }\end{array}$ & $\begin{array}{l}2.63 \\
2.45\end{array}$ & $\begin{array}{l}1.42 \\
1.47\end{array}$ & $\begin{array}{l}4.20 * \\
1.00\end{array}$ & $\begin{array}{l}1.88 \\
0.00\end{array}$ & $\begin{array}{l}1.70 \\
1.78\end{array}$ & $\begin{array}{l}0.92 \\
0.93\end{array}$ \\
\hline
\end{tabular}

Source: Agwu et al 2011; Cut off mark= 3.0 
Awareness and knowledge of climate change phenomenon is important to be able to determine its causes, impacts and adaptation measures required. Following consistent campaigns and discussions in local, national, regional and global arenas, stakeholders especially farmers have become aware of the environmental threat posed by climate change.

\section{Sources of information on agricultural innovations for climate change adaptation and food security}

Farmers had received information through varied sources but mainly through radio, television, fellow farmers, researchers, extension agents, personal observations and ministry of agriculture. Table 4 shows that the most important sources of information in Nigeria were radio and fellow farmers while in Sierra Leone the most important sources of information were radio, television and from the ministry of agriculture. In Liberia the sources of information were not significantly important

In Ghana and the Gambia, the most important sources of information were radio, extension agents, fellow farmers, and personal observations (Table 5). In the same vein, the most important sources of information in Cameroon, Equatorial Guinea and Central African Republic were extension agents and fellow farmers.
Radio has become a very useful source of disseminating agricultural information to farmers in rural areas in most African countries. This is mainly because they are affordable, easy to carry, appear in many sizes and forms including in mobile phones, receives wide networks, may not require electricity and transmits information in many languages. In this case, farmers have found it very useful in providing information and entertainment and hence a compatible partner even while working in the farms. In the same vein, television is becoming cheap and useful for farmers as they provide practical information of how to do some farm operations. The role of extension in agricultural adaptation to climate change had been described as that of dissemination of innovations on best practices and building resilience capacities of vulnerable people in climate risk management; providing feedbacks to governments and interested agencies with situation reports on the causes of climate change, its effects, and the local knowledge and practices of rural people among others (Ozor and Nnaji, 2011). According to a study by Ozor et al (2010) most farmers were aware of climate change in Southern Nigeria through observations and experience, fellow farmers and neighbours, friends, radio, television, newspapers, extension agents, conferences and workshops, and input suppliers.

Table 5: Sources of information on agricultural innovations for climate change adaptation and food security in Ghana $(n=746)$ and the Gambia $(\mathbf{n}=\mathbf{1 0 0})$

\begin{tabular}{|c|c|c|}
\hline \multirow[t]{2}{*}{ Sources } & The Gambia & Ghana \\
\hline & Percent & Percent \\
\hline Agric Extension Officers & 31 & 5.4 \\
\hline Agric extension office, farmers and radio & - & 0.1 \\
\hline Agric extension officers and radio & - & 0.3 \\
\hline Millennium Development Authority & - & 0.3 \\
\hline Other farmers & & 1.2 \\
\hline Personal observations & - & 1.1 \\
\hline Print media & 19 & 0.1 \\
\hline Radio & 12 & 50.4 \\
\hline Radio and newspaper & - & 0.3 \\
\hline Radio and other farmers & - & 1.1 \\
\hline Radio and personal observation & - & 0.1 \\
\hline Radio and television & - & 1.3 \\
\hline Radio and farmer organization & - & 0.1 \\
\hline Television & - & 0.7 \\
\hline Private agro companies e.g. WIENCO & - & 0.1 \\
\hline Forestry commission & - & 0.1 \\
\hline No response & 38 & 37.3 \\
\hline Total & 100 & 100 \\
\hline
\end{tabular}

Source: Akom-Yamga et al, 2011 
Extension activities on climate change and agriculture

Results on extension contacts with farmers in the regions show a fairly adequate advisory service to farmers on climate change and food security issues. Data in Figure 3 show that in Nigeria about $22.6 \%$ of farmers received information from extension on climate change issues through trainings and field demonstrations on the use of certain adaptive measures. Also, $25 \%$ of farmers received advice from extension on agricultural best practices to reduce impacts from climate change while $26.2 \%$ of farmers confirmed that extension agents were engaged in awareness creation on the impacts of climate change on agriculture.

Figure 3 further shows that in Sierra Leone and Liberia, $2.2 \%$ and $14.3 \%$ of the respondents, respectively confirmed of extension activities with regard to visiting sites that were affected by climate change. Similarly, $3 \%$ and $7 \%$ of them reported that there were awareness creation activities by extension on the impacts of climate change on agriculture in the areas.

In Ghana and the Gambia, about $60.9 \%$ and $95 \%$ of farmers respectively have received advisory services on climate change and food security from agricultural extension agents. However, in Ghana, farmers from the deciduous forest zone received more advisory services from extension more than all the other ecological zones. Data in Table 6 show the percentage distribution of the types of extension activities carried out in the two countries.
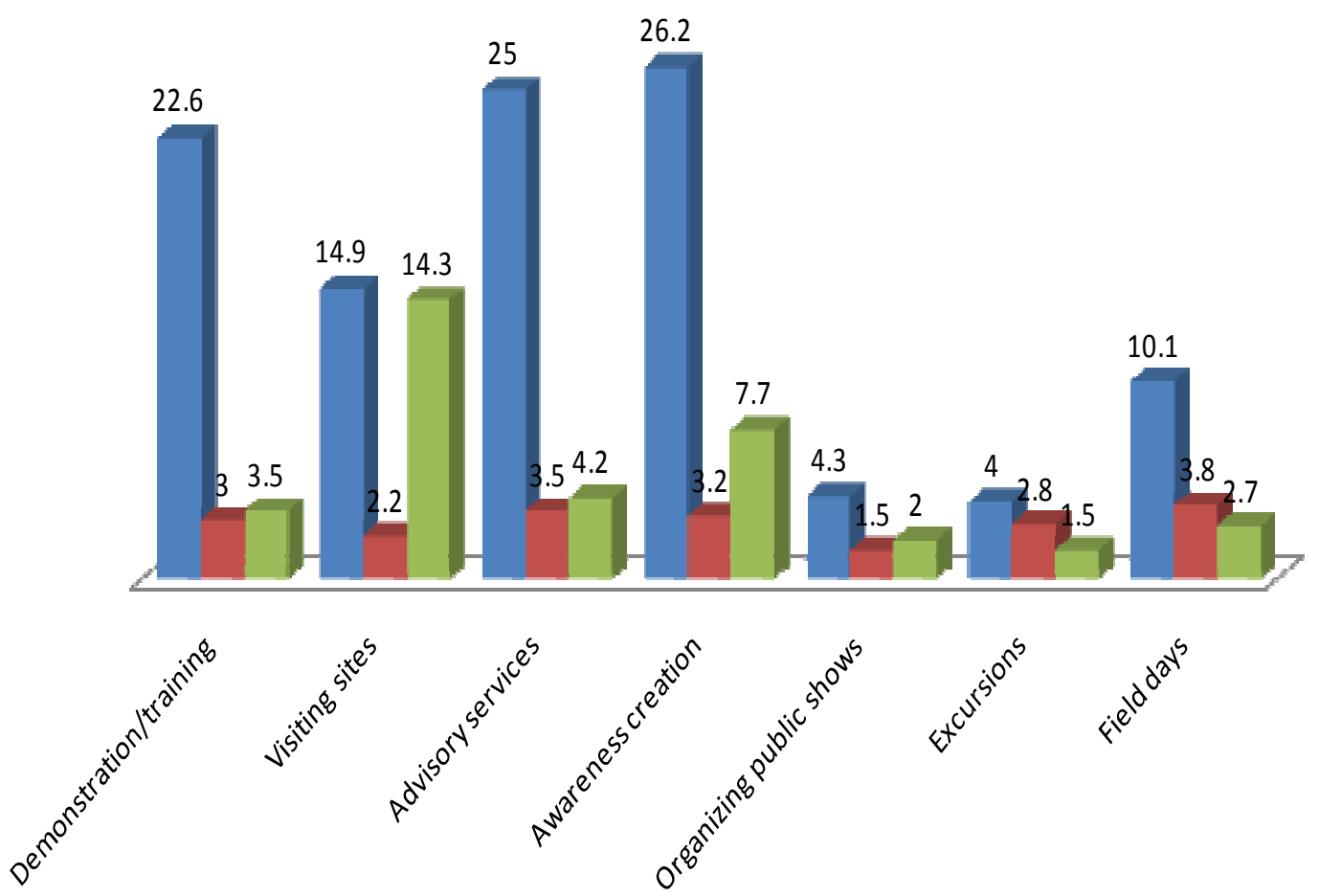

Nigeria $\quad$ SierraLeone Liberia

Figure 3: Extension activities on climate change adaptation and food security in Nigeria, Sierra Leone and Liberia.

Source: Agwu et al, 2011 
Table 6: Percentage distribution of farmers based on extension activities on climate change and food security in Ghana $(n=746)$ and the Gambia $(n=100)$

\begin{tabular}{|c|c|c|c|}
\hline $\mathbf{S} / \mathbf{n}$ & Activities & Ghana (\%) & Gambia (\%) \\
\hline & Demonstration/training on the use of adoptive measures & $14^{*}$ & 55 \\
\hline & Visiting sites that are undergoing change due to climate change & 12 & 33 \\
\hline & $\begin{array}{l}\text { Advisory services on how to manage farm to reduce the effect of climate } \\
\text { change }\end{array}$ & 17 & 24 \\
\hline & Awareness creation on the effect of climate change & 13 & 71 \\
\hline & Organizing public shows on climate change & 7 & 4 \\
\hline & Excursing showing varying climate situations & 2 & 32 \\
\hline & Field days where discussion on the effect of climate change is done & 7 & 49 \\
\hline & Other activities organized by extension agents & 8 & - \\
\hline
\end{tabular}

Source: Akom-Yamga et al, 2011. *Multiple responses

Table 7: Percentage distribution of farmers based on extension activities on climate change and food security in Cameroon, Equatorial Guinea and Central African Republic ( $n=572,115$ and 200 respectively)

\begin{tabular}{llccc}
\hline S/n & Activities & $\begin{array}{l}\text { Cameroon } \\
(\%)\end{array}$ & $\begin{array}{l}\text { Equatorial } \\
\text { Guinea (\%) }\end{array}$ & $\begin{array}{c}\text { Central } \\
\text { Republic (\%) }\end{array}$ \\
\hline 1. & $\begin{array}{l}\text { Demonstration / training on the use of } \\
\text { adaptive measures (e.g. mulching) to cushion } \\
\text { the effects of Climate change }\end{array}$ & $29.2^{*}$ & 5.2 & 33.5 \\
2. & $\begin{array}{l}\text { Visiting sites that are undergoing changes } \\
\text { due to variations in the climate }\end{array}$ & 24.3 & 0.9 & 11.5 \\
3. $\begin{array}{l}\text { Advisory services on how to manage farm to } \\
\text { reduce the effect of climate change }\end{array}$ & 20.3 & 1.7 & 17.0 \\
4. $\begin{array}{l}\text { Awareness creation on the } \\
\text { effects/consequences of climate change }\end{array}$ & 29.4 & 13.0 & 22.5 \\
5. $\begin{array}{l}\text { Organizing public shows on changing } \\
\text { climate }\end{array}$ & 3.5 & 3.5 & 3.0 \\
6. $\begin{array}{l}\text { Excursion showing varying climate } \\
\text { situations }\end{array}$ & 3.3 & 1.7 & 3.5 \\
7. & $\begin{array}{l}\text { Field days where discussions on effect of } \\
\text { climate change is discussed }\end{array}$ & 7.0 & 12.2 & 5.0 \\
\hline
\end{tabular}

Source: Ngoh et al, 2011. *Multiple responses

In Cameroon, Equatorial Guinea and Central African Republic, about 54\%, 33.5\% and $13 \%$ of farmers respectively confirmed that they had been receiving advisory services on climate change and food security from the extension service. The types of services received from extension by farmers are shown in Table 7.

Climate change presents new challenges and threats to food security in most countries especially the developing ones (Ozor and Nnaji, 2011). According to Ozor (2009), there is need for change in roles and capacity in the extension system so as to accommodate the new dimensions brought about by climate change. In order to provide practical solutions to hazards and sudden uncertainties in agricultural production, there is need for improved extension services in rural areas to build the resilience capacity of farmers against climate change and food security risks including flooding, erosion, acid rains, drought, submergence and poisoning from agricultural chemicals (insecticides, pesticides, herbicides, fertilizers, etc).

Innovative strategies for climate change adaptation and food security

. Data in Table 8 show that the most popular adaptation measures used in Nigeria were; mulching/use of cover crops (74.1\%), increased weeding (63.9\%), prayers for God's intervention $(58.1 \%)$, increased use of fertilizers and seeds (57\%), use of chemicals such as herbicides and pesticides $(55.3 \%)$ intensive manure application (53\%), and processing crops to minimize post-harvest losses $(51.8 \%)$. The most popular adaptation options in Sierra Leone were; prayers for God's intervention (70\%) increased weeding $(62.2 \%)$ and increased use of fertilizers and seeds (60\%); while the most popular adaptation measures in Liberia were; increased weeding $(74.4 \%)$ and prayers for God's intervention (60.6\%). 
Table 8: Percentage distribution of farmers based on innovative measures adopted for climate change adaptation over the past five years in Nigeria, Sierra Leone and Liberia ( $n=624,400$ and 400 respectively)

\begin{tabular}{|c|c|c|c|}
\hline Innovative climate change adaptation measures used by farmers & Nigeria & Sierra Leone & Liberia \\
\hline Ground water harvesting & $11.9^{*}$ & 37.6 & 18.1 \\
\hline Mulching / use of cover crops & 74.1 & 5.4 & 5.0 \\
\hline Cultivating in wetlands / river valleys (e.g. Fadama) & 17.8 & 45.5 & 14.9 \\
\hline Construction of drainage systems & 26.3 & 12.9 & 8.1 \\
\hline Planting of trees & 23.3 & 4.9 & 3.7 \\
\hline Use of resistant varieties & 38.7 & 5.0 & 5.0 \\
\hline Processing crops to minimize post-harvest losses & 51.8 & 15.7 & 4.3 \\
\hline Expansion of cultivated land area & 26.3 & 44.3 & 27.6 \\
\hline Increased use of fertilizers, seeds & 57.0 & 60.0 & 11.6 \\
\hline Intensive manure application & 53.0 & 20.0 & 5.0 \\
\hline Increased weeding & 63.9 & 62.2 & 74.4 \\
\hline Use of chemicals: herbicides, pesticides etc & 55.3 & 10.0 & 11.3 \\
\hline Moved to a different site & 19.1 & 51.8 & 47.8 \\
\hline Change in the timing of land preparation activities & 30.1 & 10.3 & 18.7 \\
\hline Changes in planting dates & 38.0 & 40.4 & 21.8 \\
\hline Practicing zero / minimum tillage & 38.5 & 4.5 & 3.4 \\
\hline Changes in harvesting dates & 30.0 & 36.4 & 15.8 \\
\hline Multiple cropping (planting of many crops in the same piece of land) & 42.9 & 49.1 & 37.2 \\
\hline Mixed farming (crop and animal production) & 29.4 & 9.7 & 7.7 \\
\hline Relay cropping - planting and harvesting in succession & 14.2 & 39.8 & 2.9 \\
\hline Intercropping - main crops planted with subsidiaries at low densities & 19.0 & 42.4 & 14.7 \\
\hline Decreasing animal stock & 11.9 & 0.7 & 1.9 \\
\hline Change from animal production to crop production & 8.4 & 0.2 & 1.7 \\
\hline Prayers for God's intervention & 58.1 & 70.0 & 60.6 \\
\hline Planting of early maturing crops & 30.8 & 41.1 & 3.8 \\
\hline
\end{tabular}

Source: Agwu et al, 2011. *Multiple responses

The results on innovative strategies for climate change adaptation in Nigeria, Sierra Leone and Liberia indicate that increased weeding of farms and prayers for God's intervention were the most common measures across the three countries studied. One of the dreadful impacts of climate change for farmers is intense weed growth. Farmers noted during the FGDs that they had to weed their farms more than thrice if they were to get meaningful harvests from it. Studies have shown that changes in climate breeds intense weed growth due to favourable conditions for the weeds to grow such as moisture and heavier than normal rainfall in some places which also lead to erosion and increased dispersion of weeds from one place to another (Ministry of Environment of the Federal Republic of Nigeria, 2003). According to Ozor and Nnaji (2011) the implication of high incidence of weeds on farmlands is that it increases the cost of production through payments for labour or use of herbicides. It is interesting to find out that farmers in this region relied on prayers for God's intervention in normalizing the changing climate. According to the farmers "God can reverse the changes in climate to the usual normal conditions". This faith in God has sustained many of the farmers and some usually offer sacrifices at the beginning of every planting season to prevent any adverse effects on their crops and hence ensure a bumper harvest.
Farmers noted that this measure have worked for them in most cases.

In Ghana and the Gambia, farmers adopted several innovative measures to cushion the effects of low rainfall, excessive rainfall and incidences of pests and diseases in their farms. Most farmers in Ghana and the Gambia (29.8\% and $33 \%$ respectively) did not do anything to change the low rainfall situation when it arises. By this they depend on nature and pray for God's intervention. In addition however, farmers in Ghana choose to weed their farms regularly $(22.7 \%)$ in order to reduce the weed competition for moisture with the main crops. Similarly, during excessive rainfall, most farmers in Ghana and the Gambia (50\% and $23 \%$ respectively) still did nothing to help the situation. However, others engaged in the construction of trenches and drainage system in their farms and homestead (18\% and 5\% respectively) to hold back the floods or channel them properly to areas where it will not destroy farms and property. In order to cope with incidences of pests and diseases arising from changes in the climate, most farmers in Ghana and the Gambia (60.2\% and $48 \%$, respectively) had adopted the use of agrochemicals such as pesticides, insecticides, and herbicides in combating the menace. About $5.6 \%$ and $39 \%$ of farmers in Ghana and the Gambia respectively have also resorted to seeking advice from agricultural extension professionals. 
From the foregoing, it could be inferred that the inaction by most farmers in Ghana and the Gambia was due to lack of modern technologies and innovations for climate change adaptation such as use of irrigation technologies during low rainfall, proper network of drainage systems in homesteads and farms and weather forecast technologies to alert farmers of impending vagaries in rainfall or other weather conditions. The inaction also suggests lack of requisite capacity by farmers to adapt to climate change impacts. Low adaptive capacity refers to the inability of a people to effectively and efficiently cope with the incidences of climate change impacts under a particular condition and time (Ozor, 2010). Africa's high vulnerability to climate change has been linked to its low adaptive capacity (Ozor, 2009; IPCC, 2007). This is as a result of numerous factors but most importantly the lack of income, absence of reliable institutions to provide required capacity to cope, and lack of government support and goodwill (Ozor, 2009).

The innovative strategies for climate change adaptation and food security in Cameroon, Equatorial Guinea and Central African Republic collated through the FGDs conducted in the various countries show that the most popular adaptation strategies adopted by farmers in the countries were; late planting, blocking of drainage outlets in rice farms to conserve water, grazing on leftover straws and harvest of animal droppings, multiple cropping and planting of crops with different maturity periods, wood ash application, and urban cropping. Other strategies include planting of shade trees, river bank farming, and soil aeration with fungicides.

In the event of delayed rainfall in Cameroon, Equatorial Guinea and Central African Republic, crop farmers had embarked on a strategy of late planting for at least one month and repeated planting of the crops in response to the erratic rainfall. This was an innovative strategy for maize, millet and Cucurbitaceae (Cucumeropsis edulis) and other cereal crop. Again in most rice farms in the northern plains of the study area, prolonged dryness compelled farmers to block drainage outlets in order to maintain some degree of water logging within the farms. This practice aims to conserve moisture for the development of the rice plant. Furthermore, since conflict usually arises between the rice farmers and cattle grazers over the use of available wet land, a system is locally practiced where rice farmers, after the harvest allow grazers to utilize the left over straw to feed cattle. In return to this offer, the farmers gain the droppings from the grazing cattle that eventually aid in the fertilization of the farms plots. This is an innovation that has gone a long way to reduce farmer grazer conflict in the Fadama plains of Cameroon especially with seasonal variations in precipitation.

Again, food crop farmers have equally developed multiple cropping and planting of species that mature at different periods so as to compensate for the late maturity and failures of some crops in the event of climate variability to ensure continuous supply of food. In some areas, rotational cropping has been the order of the day where another crop is planted immediately after the harvest of the first crop. This is common in monomodal agro-ecological zones of Cameroon where the harvesting of maize in July, August and September is preceded immediately by the preparation of land for the planting of various species of beans. Again, during land preparation and planting, farmers apply wood ash on the soils as a local insecticide to prevent the destruction of the germinating seedlings by nematodes and other soil-borne diseases and pests. Farmers noted that this practice has saved their crops and limited their application of agrochemicals which is costly and harmful.

Furthermore, the limited availability of post harvest preservation techniques undermines the supply of food and vegetables from the rural settlements to the urban areas. Most urban households have replaced flower gardens with small scale gardens for the continuous supply of perishable vegetables. Ornamental trees are now giving way to fruit trees and permanent crops like plantains. Formerly, market gardeners used to nurse seedlings in the last two weeks of September and transplanted to the farms in the first two weeks of October. Faced with the exigencies of climate change (especially prolonged rains), today, the nursing period has been moved from the last two weeks of September to the last two weeks of October in countries studied with effective transplanting of seedlings to the farms taking place in November. Other innovative strategies adopted by farmers in the central African region include planting of shade trees. In this case, perennial crop farmers (palms, cocoa, coffee, etc) confronted with the problem of prolonged dryness are now leaving selected trees in their farms to provide shades for other crops and hence reduce the scorching heat of the sun on the crops. Many farmers also adopt river bank farming method where farmers (cocoa and coffee farmers) now concentrate their new farms along river beds as a means of guaranteeing moisture supply during the dry season. Palm farmers prune their farms and use the pruned leaves as mulch to cover the ground below the palms to conserve soil moisture. This in effect helps the palm trees cope and survive through these long dry periods. Yet other 
farmers do aerate and treat their soils to reduce the impact of micro organisms that attack cocoa and coffee pods which do proliferate during prolonged rains. Farmers use fungicides to curb the microbial load on the farms. Regular cleaning of farms encourages total aeration and contributes to the reduction of the microbial load on these farms.

\section{CONCLUSION AND RECOMMENDATIONS}

The study sought to identify the indigenous and emerging agricultural innovations for climate change adaptation in western and central Africa including Nigeria, Sierra Leone, Liberia, Ghana, Gambia, Cameroon, Equatorial Guinea, and Central African Republic. Based on the major findings from the study it can be concluded that most farmers in the study area were in their productive ages and were mainly male headed households. The farmers were literate enough to communicate and had longstanding experience in farming but possessed no special training on climate change adaptation to ensure food security. They owned small farms and were mainly crop farmers. Most of the farmers were aware and knowledgeable about climate change and have mostly received information on climate change from radio. Extension activities were going on especially the creation of awareness on climate change issues but information disseminated was very limited. The most popular innovative approach for adaptation was regular weeding of farms and prayers for God's intervention.

It is therefore recommended that relevant stakeholders in the agricultural innovation system including farmers, extension agents, researchers, and policymakers be actively engaged in developing innovations for adaptation. Farmers will need supports from governments through effective policies for innovation development and the provision of essential inputs such as drought tolerant seeds, agrochemicals, farm machinery, and infrastructure such as good roads, electricity, markets, potable water and well trained agricultural extension personnel. Farmers on the other hand need to pull resources together through cooperative unions in order to realize economies of scale and be able to access credits that may be needed for adaptation and agricultural production. The private sector actors need to be actively involved in the development of innovations for climate change adaptation especially by working together with other stakeholders including farmers, researchers, and the civil society in a fovourable policy environment. Finally, efforts should be made to organize fora (training workshops, field days and seminars, etc) for capacity building and strengthening for all stakeholders especially farmers and extension personnel on best practices and emerging innovations for climate change adaptation and food security in Africa.

\section{ACKNOWLEDGEMENT}

This paper was produced as part of the implementation of the African Technology Policy Studies Network (ATPS) Phase VI Strategic Plan, 2008 - 2012 funded by ATPS Donors including the Ministerie van Buitenlandse Zaken (DGIS) the Netherlands, Rockefeller Foundation, amongst others. The authors hereby thank the regional research coordinators represented by their principal investigators namely; Agwu, et al (Nigeria, Sierra Leone and Liberia); Akon-Yamga, et al (Ghana and Gambia); and Ngoh, et al (Cameroon, Sierra Leone and Liberia) for their efforts in the research process.

\section{REFERENCES}

Adisa B. and Okunade E. O. (2005). Women in agriculture and rural development, In: Adedoyin S. Fola (ed). Agricultural Extension Ilorin: AESON, ARMTI: pp. 69-77.

Agwu, E. A. and Anyanwu, A. C. (1996). Sociocultural and Environmental Constraints in Implementing the NALDA Programme in South eastern Nigeria. A case study of Abia and Enugu State. Journal of Agriculture and Education Vol. 2, pp. $68-72$.

Agwu, A. E., Egbule, C., Amadu, F.A., Morlai, T. A., Wollor,E. T., and Cegbe, L.W., (2011). Agricultural Innovations for Climate Change Adaptation and Food Security in Nigeria, Sierra Leone and Liberia: Empirical Evidence. Technical Report submitted to the ATPS, Nairobi, Kenya.

Akon-Yamga, G., Boadu, P., Obiri, B. D., Amoako, J. and Mboob, F. J., (2011). Agricultural Innovations for Climate Change Adaptation and Food Security in Africa: The Cases of Ghana and the Gambia; Technical Report submitted to the ATPS, Nairobi, Kenya.

Challinor, A. J., Ewert, F., Arnold, S., Simelton, E., Fraser, E., (2009). Crops and climate change: progress, trends, and challenges in simulating impacts and informing adaptation. J. Exp. Bot. 60, 2775-2789.

Food and Agricultural Organization of the United Nations (FAO), (2008). The State of Food and Agriculture, Rome, Italy. 
Intergovernmental Panel on Climate Change, IPCC Fourth Assessment Report AR4. Climate Change (2007): Impacts, Adaptation and Vulnerability. Contribution of Working Group II to the Fourth Assessment Report of the Intergovernmental Panel on Climate Change. M.L. Parry, O.F. Canziani, J.P. Palutikof, P.J. van der Linden and C.E. Hanson, Eds. Cambridge University Press, Cambridge, UK: 976 pp.

Ministry of Environment of the Federal Republic of Nigeria (2003). Nigeria's First National Communication under the United Nations Framework Convention on climate change. Abuja, Nigeria.

Millennium Development Goal Report (2006). Millennium Development Goals Report. United Nations, New York.

Ngoh, S. B., Mafany, G. T. and Ndeso, S. A. (2011). Agricultural Innovations and Adaptations to Climate Change Effects and Food Security in Central Africa: Case of Cameroon, Equatorial Guinea and Central Africa Republic; Technical Report submitted to the ATPS, Kenya.

Ozor, N. and Nnaji, C. (2011). The role of extension in agricultural adaptation to climate change in Enugu State, Nigeria; Journal of Agricultural Extension and Rural Development, Vol. 3(3): 42 - 50.

Ozor, N. and Nnaji C. (2010). Difficulties in adaptation to climate change by farmers in Enugu State, Nigeria; Journal of Agricultural Extension, Vol. 14(2): 106 $-122$.

Ozor, N.; Madukwe, M.C.; Onokala, P.C.; Enete, A.; Garforth, C.J.; Eboh, E.C.; Ujah, O.; and Amaechina, E. (2010). A framework for Agricultural Adaptation to Climate Change in Southern Nigeria; A research report of the Development Partnerships in Higher Education (DelPHE) 326 Executive Summary supported by DFID and the British Council, Enugu; African Institute for Applied Economics: 8pp.

Ozor N. (2009). Implications of Climate Change for National Development: The Way Forward. Debating Policy Options for National Development; Enugu Forum Policy Paper 10; African Institute for Applied Economics (AIAE); Enugu, Nigeria, pp. 25-42. 